\title{
Heuristic Evaluation of Children's Authoring Tool for Game Making
}

\author{
Laili Farhana Md Ibharim*, Maizatul Hayati Mohamad Yatim \\ Universiti Pendidikan Sultan Idris, Malaysia \\ *life_farhana@yahoo.com
}

\begin{abstract}
The main purpose of the study is to evaluate the heuristic inspection of children's authoring tools to develop games. The researcher has selected 15 authoring tools for making games specifically for educational purposes. Nine students from Diploma of Game Design and Development course and four lecturers from the computing department involved in this evaluation. A set of usability heuristic checklist used as a guideline for the students and lecturers to observe and test the authoring tools selected. The study found that, there are just a few authoring tools that fulfil most of the heuristic requirement and suitable to apply to children. In this evaluation, only six out of fifteen authoring tools have passed above than five elements in the heuristic inspection checklist. The researcher identified that to develop a usable authoring tool developer has to emphasis children acceptance and interaction of the authoring tool. Furthermore, the authoring tool can be a tool to enhance their mental development especially in creativity and skill.
\end{abstract}

Keywords: Authoring tool, children, game making, Heuristic

\section{Introduction}

Digital games have been the current trend that has gained a place among our society today. In fact, teachers and educators also agreed the positive impact of digital games as one of teaching aids in teaching and learning process until the realization of Game-Based Learning (GBL) term in education (Connolly, Stansfield \& Boyle, 2009). With the involvement with GBL, it is necessary to provide the exposure and opportunity to the children to show their talents and abilities in making proposed digital games. Do we ever thought what are the best tools to help them accomplish the task? The expansions of technology nowadays cause many software companies competing against each other to produce tools that able to gain wider share in the market. The authoring tool is one of software application that now gaining momentum among consumers to facilitate their work. However, there are issues of concern relating to the usability of authoring tool in the development of digital games, particularly to children. The objective of this study is to examine the heuristic usability of authoring tools for making digital games for children that are available for free online.

\section{Literature Review}

Children in Making Games: A child's ability in designing digital games should be supported. The rapid development of digital games today allow a child instead as a player, they also can be a designer. According to Kafai in (Baytak, Land \& Smith, 2011), she emphasized that children are encouraged to become "producer" rather than "consumer" of a computer. While playing, the kids express their comment or suggestion about the game through their speech and behaviour. This happens spontaneously without being influenced by the external environment and person. Child-related issues in technology and human computer interaction (HCI) more spectacular discussed at seminars and conferences around the world. The first conference paper written by Malone discussed matters relating to children's use of games. He had proposed general HCI guidelines for designing enjoyable user interfaces (Druin, 2002). In the early year of HCI and children introduction, the researchers have only highlighted issues related to the impact of new technology on children's learning. Today, researchers have found a new direction in enhancing the development of the technology parallel to the ability to develop future learning experiences more effective and meaningful. Druin has set four main roles of children in the design of new technologies. The involvement of children in the different roles is based on the design process and goals of the product. Children will be involved directly in the research and development process. Researchers will be able to see and understand the effectiveness of an existing product to a child when it comes to them as a user, tester, informant and design partner to design improvements for future products for their needs and understanding (Druin, 2002) and (Laili Farhana, 2011). Based on previous studies involving children in the digital games, some researchers have started to expand the child's role to become a designer of digital 
games especially in the field of education (Lim, 2008; Prensky, 2008). As a study conducted in (Baytak, Land \& Smith, 2011) the findings show the understanding and readiness of children to learn become more improved when they design their own games. They can show their personal opinions according to their own creativity and make them appreciate and take pride in the resulting game produced. This is further supported by a study conducted in (Kamisah \& Nurul Aini, 2013) which proved the activities of game design can facilitate the exchange of knowledge among students and to provide students an enjoyable learning environment appropriate with the needs of 21st century skills.

Authoring Tool for Children: Introduction of game making as an approach in class is gaining a positive acceptance by teachers (Kamisah \& Nurul Aini, 2013) and (Yatim \& Masuch, 2007). However, children and teachers are not a professional games programmer and designer. They need a tool to help them develop digital games as well as professional practitioners. At the beginning of the emergence of computer-based learning (CBL), an application known as computer-assisted instruction (CAI) has been introduced to help the novice user to develop software and computer applications. One of the intended applications is authoring tool. An authoring tool is a software application, which is used by nonprogrammers, who use the metaphor (Hall, 2001) and it is an integration of content and functionality that gathers a project developed (Vaughan, 2001). There are a variety of multimedia applications and products can be developed using authoring tools in important areas such as advertising, entertainment, simulation, presentation and education. The utilization of an authoring tool for making digital games for kids, it can be referred to as software that allows children to develop or design a digital game according to the principles and guidelines in the theory of constructivism (Maizatul Hayati, 2009). There are three types of strategies practiced in an authoring tool which is a card or page base (toolbook and hypercard), icon base (available in the library) and time base (timeline frames). Children can develop digital games using a template provided by the authoring tool or designing the game from scratch. Some of available authoring tools for making digital games and often used by young children is like e-Adventure, Shai Scenario Editor, The Alice, Stagecast Creator and Game Maker (Maizatul Hayati, 2009; Mehm, Konert, Göbel \& Steinmetz, 2011). Each authoring tool has its own differences in programming style, feature and function are provided as well as its ability to produce the desired product. Good selection of authoring tools that can save time, and make it easier for children to create something unique and meaningful. Some of the criteria for selection of good authoring tools are ease of use, high level of engagement, interoperability, adequate specifications and contents that are relevant to the current situation.

Heuristic evaluation for children product: Usability is an important aspect in the evaluation of computer systems or multimedia interactive products. Three important aspects of usability evaluation are the effectiveness of the products needed to solve the task, the efficiency of the user using the product and consumer satisfaction in the performance of the product (Dix, 2004). One of the methods to evaluate the usability is known as Heuristic inspection introduced by Nielsen and Molich where users and experts will look at the usability problems of a product based on predefined sets. Nielsen also released a few sets of Heuristic guidelines especially for user interface design and website design for children (Nielsen, 2013). Usually, the analysis is carried out on an existing product or during the development life-cycle to produce a better product. The advantages of Heuristic inspection in this process are cheaper, intuitive, non-formal, flexible and time saving. In order to produce a usable authoring tool for children in making their own games, a variety of studies involving multidisciplinary from various fields of knowledge combined to see three important aspects which are activities of design, programming and playing digital games. Experts also need to understand their main user (children), especially how children will react in certain situations such as an error occur or technical problem while using the authoring tool. This method has been practiced by many previous studies such as Nielsen \& Molich (1990), Shneiderman \& Plaisant (1997), Gilutz \& Nielsen (2002), Chiasson \& Gutwin (2005) and many more. Next, a set of guidelines may generate and it will improve from time to time to enable other developers and designers to produce a quality product. The table below is a summary of Heuristic inspection sets that can be gathered from research and resources identified for an authoring tool for children (Maizatul Hayati, 2009).

Table 1: Usability Heuristic Inspection

\begin{tabular}{ll}
\hline Aspect & Description \\
\hline Consistency & $\begin{array}{l}\text { Ease of use, visual consistency, content-specific metaphors and as minimum text as } \\
\text { possible. }\end{array}$ \\
Child- & $\begin{array}{l}\text { Putting together the concept of game design and interface design for children, including } \\
\text { friendliness }\end{array}$ \\
children's familiarities and age-appropriateness.
\end{tabular}


functionality games, including producing games that have been supported by the collection of resources such as pictures, sound and interactivity.

Staying in the Providing leverage and exciting environment for children to explore different domains of flow knowledge in order to capture their interest.

Reflection Indication for children to refine their ideas about the games they are making.

Familiar Emphasis on the content area skills including game design, control design, elements conceptual design and game mechanics.

model

Familiar way Understandable style of scripting and authoring that is appropriate for the children's to program task.

\section{Methodology}

Participant and location: The study was conducted against a group of students of Diploma Game Design and Development, UPSI (semester 4). A total of nine students (3 girls and 6 boys) divided into three groups. The distribution of the group members is divided according to the students' interests where since the first semester, each student has been identified their skills and knowledge of digital game design and programming. They act as an assessor in user's perspective. Addition, four lecturers from the Department of Computing is also involved in this study. The lecturers are experienced in the field of multimedia, digital games and children for more than three years. They serve as evaluators of expert view. The study was carried out in the game laboratory, UPSI. The laboratory was chosen because it has wide space and equipped with facilities. Participants will feel comfortable and the study can be carried out effectively and systematically (Laili Farhana, 2011; Maizatul Hayati, 2009).

Instruments and procedures: The observation guided by a set of Heuristic inspection checklist that contains 15 types of authoring tools chosen by the researcher. These authoring tools were selected based on user age appropriateness (children aged 7 to 12 years) from the website Games in education: Game Creation Tools (http://gamesined.wikispaces.com). The Heuristic inspection set contains seven elements of usability indicator as the Table I. The study was conducted in two phases. The first phase involves only students while the second phase involves the students and lecturers. Research strategy is as follows:

\section{TABLE 2: STRATEGY OF THE STUDY}

\begin{tabular}{ll}
\hline Phase & Activity \\
\hline 1 & Each group was given a set of Heuristic inspection checklist to assess five types of authoring \\
& tools distributed to each group randomly. \\
& Group 1: Scratch, Atmophir, Gamestar Mechanic, Game Salad and Adventure Maker. \\
& Group 2: Stencylworks, Construct, Sploder, Toontalk and Alice. \\
& Group 3: Game Editor, Kodu, Agent Sheet, Gamefroot and Squeak Etoys. \\
& The discussions between group members by emphasizing the aspects of usability, interface and \\
& playability based on the checklist.
\end{tabular}

Table 2 (continue)

\begin{tabular}{ll}
\hline Phase & Activity \\
\hline 2 & Each group presents their findings in front of the lecturers to be evaluated in more detail. \\
& Authoring tools that meets to the elements contained in the checklist will be identified. \\
\hline
\end{tabular}

\section{Results and Discussion}

According to the data obtained from Table 3, we can see six authoring tools to game making for children that passed more than five elements in the set of Heuristic inspection. There are Scratch (Figure 1), Atmosphir (Figure 2), Stencylworks (Figure 3) and Game Salad (Figure 4). Meanwhile Gamestar Mechanic (Figure 5) and Gamefroot (Figure 6) meet the entire usability elements. The six authoring tool has quite similar features and functionality that suitable for use by children and novice users to develop their own games. The results of the observation are summed up as follows: 
Table 3: Heuristic Inspection Data Collection

\begin{tabular}{|c|c|c|c|c|c|c|c|c|c|c|c|c|c|c|c|}
\hline $\begin{array}{l}\text { Elements/ } \\
\text { Authoring } \\
\text { Tools }\end{array}$ & 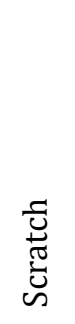 & 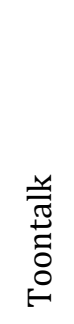 & 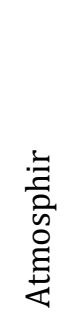 & 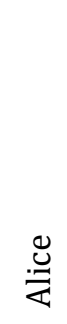 & 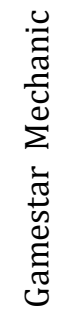 & 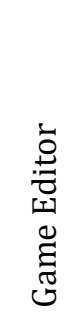 & 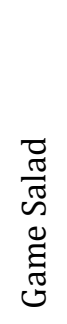 & $\begin{array}{l}z \\
0 \\
2\end{array}$ & 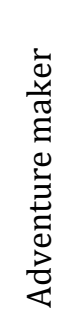 & 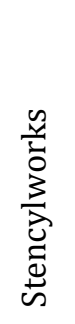 & 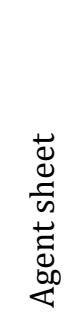 & 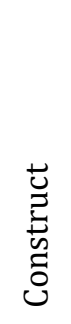 & 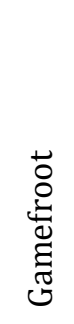 & $\frac{\bar{d}}{\frac{0}{2}}$ & 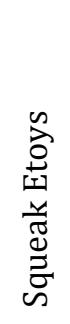 \\
\hline $\begin{array}{l}\text { Child } \\
\text { friendliness }\end{array}$ & $\mathrm{X}$ & $\mathrm{X}$ & $\mathrm{X}$ & & $\mathrm{X}$ & & $\mathrm{X}$ & & & $\mathrm{X}$ & & & $\mathrm{X}$ & $\mathrm{X}$ & \\
\hline $\begin{array}{l}\text { Degree of } \\
\text { functionality }\end{array}$ & $\mathrm{X}$ & $\mathrm{X}$ & $\mathrm{X}$ & & $\mathrm{X}$ & & & $\mathrm{X}$ & $\mathrm{X}$ & $\mathrm{X}$ & & $\mathrm{X}$ & $\mathrm{X}$ & $\mathrm{X}$ & $\mathrm{X}$ \\
\hline $\begin{array}{l}\text { Staying in } \\
\text { the flow }\end{array}$ & & $\mathrm{X}$ & & & $\mathrm{x}$ & & $\mathrm{X}$ & $\mathrm{X}$ & & & & $\mathrm{X}$ & $\mathrm{X}$ & $\mathrm{X}$ & $\mathrm{X}$ \\
\hline Reflection & $\mathrm{X}$ & $\mathrm{X}$ & & $\mathrm{X}$ & $\mathrm{X}$ & & $\mathrm{X}$ & & $\mathrm{X}$ & $\mathrm{X}$ & & $\mathrm{X}$ & $\mathrm{x}$ & $X$ & \\
\hline $\begin{array}{l}\text { Familiar } \\
\text { conceptual } \\
\text { model. }\end{array}$ & & & $\mathrm{X}$ & $\mathrm{X}$ & $\mathrm{X}$ & & $\mathrm{X}$ & $\mathrm{X}$ & & $\mathrm{X}$ & $\mathrm{X}$ & & $\mathrm{X}$ & & $\mathrm{X}$ \\
\hline $\begin{array}{l}\text { Familiar } \\
\text { way } \\
\text { program }\end{array}$ & $\mathrm{X}$ & & $\mathrm{X}$ & $\mathrm{X}$ & $\mathrm{X}$ & $\mathrm{X}$ & $\mathrm{X}$ & & & $\mathrm{X}$ & $\mathrm{X}$ & & $\mathrm{X}$ & & \\
\hline Consistency & $\mathrm{X}$ & & $\mathrm{X}$ & & $\mathrm{X}$ & $\mathrm{X}$ & & & & & & $\mathrm{X}$ & $\mathrm{X}$ & & $\mathrm{X}$ \\
\hline TOTAL & 5 & 4 & 5 & 3 & 7 & 2 & 5 & 3 & 2 & 5 & 2 & 4 & 7 & 4 & 4 \\
\hline
\end{tabular}

User Acceptance: Adult acceptance against the technology is very different from children. Therefore they require an authoring tool that appropriates with age group especially the interface design should be aesthetic, easy to understand, easy to follow and simple as recommended by Nielsen (Nielsen, 2013). In addition, children should also be familiar with the concept of the environment authoring tool with real world. For example, Game Salad uses the concept of adventure that requires the character to run, jump and walk to get the reward as seen on other digital games. Programming strategy in Scratch that uses the puzzle approach common played in Lego games in the real world. It makes easier for the child who wants to plan their game design and it will make the authoring tool is easy to follow. Furthermore, it will help to reduce the memory load of children to learn something new from scratch (Maizatul Hayati, 2009). A good authoring tool is easily available because it is open source, portable, and has a high level of engagement and fun. Teaching and learning process become exciting when the authoring tool suited applied (Kamisah, \& Nurul Aini, 2013; Yatim \& Masuch, 2007).

Interaction between User and Authoring Tool: In the area of $\mathrm{HCI}$, the methodology used to design multimedia products specifically for children known as child-centered design (CCD), which was adapted from user-centered design (UCD) (Laili Farhana, 2011; Maizatul Hayati, 2009). In CCD, interaction design with children (IDC) should be given special emphasis where every navigation and features in authoring tools have to function properly. A good authoring tool should use simple icons that can be seen and understood by children. Moreover, each authoring tool should allow children to operate freely and no confusing instructions that cause children feel frustrated and bored. Provision of interactive galleries as 
provided by Gamefroot and Gamestar Mechanic makes children able to diversify the idea of the game's storyline to encourage their ability as digital game designer.

Creativity and Skill of Children: Creating is the highest level in Bloom's taxonomy and supported by constructivist learning theory (Yatim \& Masuch, 2007). A good authoring tool may assist children in designing something new, unique and particularly useful digital games in educational value. Children can create their own idea in the form of digital games that may be beyond our expectations (Maizatul Hayati, 2009). In addition, their experience and mental modal can make this child become more skillful in terms of technical skill and soft skill. For example, Atmosphir and Stencylworks provide a platform that allows a child to disclose their imagination into the design of digital games that can be shared with other colleagues. This will improve their self-esteem and motivation in order to produce an innovation and creative generation.

\section{Conclusion}

A good selection of authoring tools is the backbone that contributes to the success of a multimedia product, especially for novice users and children. Rapid development of authoring tools for making digital games for kids, it is believed to bring a new paradigm in the digital games industry and education. Children need to be exposed to the experience of developing their own digital games to prove the creativity and skills to be a glorious cyber generation for a better nation.

Acknowledgment: The study described in this paper has been supported financially by the Government of Malaysia (PRGS 2012-0092-107-32) and technically by Research Management and Innovation Center, Universiti Pendidikan Sultan Idris. The researcher would like to thank the students and lecturers from Computing Department, Faculty of Art, Computing and Creative Industry, who took part in the study for sharing their thoughts and give fully cooperation.

\section{References}

Baytak, A., Land, S. M. \& Smith, B. K. (2011). Children as Educational Computer Game Designers: An Exploratory Study. TOJET, 10(4).

Chiasson, S. \& Gutwin, C. (2005). Design principles for children's technology. Technical report HCI-TR-0502, Computer Science Department, University of Saskatchewan, Canada.

Connolly, T., Stansfield, M. \& Boyle, L. (2009). Games-based learning advancements for multi-sensory human computer interfaces: Techniques and effective practices. Information Science Reference.

Dix, A. (2004). Human computer interaction. Pearson Education.

Druin, A. (2002). The role of children in the design of new technology. Behaviour and information technology, 21(1), 1-25.

Gilutz, S. \& Nielsen, J. (2002). Usability of websites for children: 70 design guidelines. http://www.nngroup.com/reports/kids/

Hall, B. (2001). New Technology Definitions. www.brandonhall. com/ public/glossary/index.htm.

Kamisah, O. \& Nurul-Aini, B. (2013). Teachers and Students as Game Designers: Designing Games for Classroom Integration. In S. de Freitas, M. Ott, M. Popescu, \& I. Stanescu (Eds.), New Pedagogical Approaches in Game Enhanced Learning: Curriculum Integration (pp. 102-113). Hershey, PA: Information Science Reference. doi:10.4018/978-1-4666-3950-8.ch006.

Laili Farhana, M. I. (2011). An Alternative Method for Collecting and Gathering Data Using Smartboard Application In The Field of Interaction Design and Children (IDC). Master Dissertation, Universiti Pendidikan Sultan Idris, Malaysia.

Lim, C. P. (2008). Spirit of the game: Empowering students as designers in schools. British Journal of Educational Technology, 39(6), 996-1003.

Maizatul Hayati, M. Y. (2009). Children, Computer and Creativity: Usability Guidelines for Designing A Game Authoring Tool for Children. PhD Dissertation, Otto-Von-Guericke University of Magdeburg, Germany.

Mehm, F., Konert, J., Göbel, S. \& Steinmetz, R. (2012). An authoring tool for adaptive digital educational games. In 21st Century Learning for 21st Century Skills (pp. 236-249). Springer Berlin Heidelberg.

Nielsen, J. \& Molich, R. (1990). Heuristic evaluation of user interfaces. In Proceeding of the SIGCHI conference on Human factors in computing systems (pp.249-256). ACM. 
Nielsen, J. (2013). Nielsen Norman Group: Evidence-Based User Experience Research, Training, and Consulting. http://www.nngroup.com.

Prensky, M. (2008). Students as designers and creators of educational computer games: Who else? British Journal of Educational Technology, 39 (6), 1004-1019.

Shneiderman, B. \&Plaisant, C. (1997). Designing the user interface: Strategies for effective HumanComputer Interaction. Boston,USA: Addison-Wesley.

Vaughan, T. (2001). Multimedia: Making It Work (Fifth Edition). Osborne/ McGrawHill.

Yatim, M. H. \& Masuch, M. (2007). Educating Children through Game Making Activity. http://www. learnit. org.gu.se/digitalAssets/862/862887_yatim_masuch. Pdf, 2007.

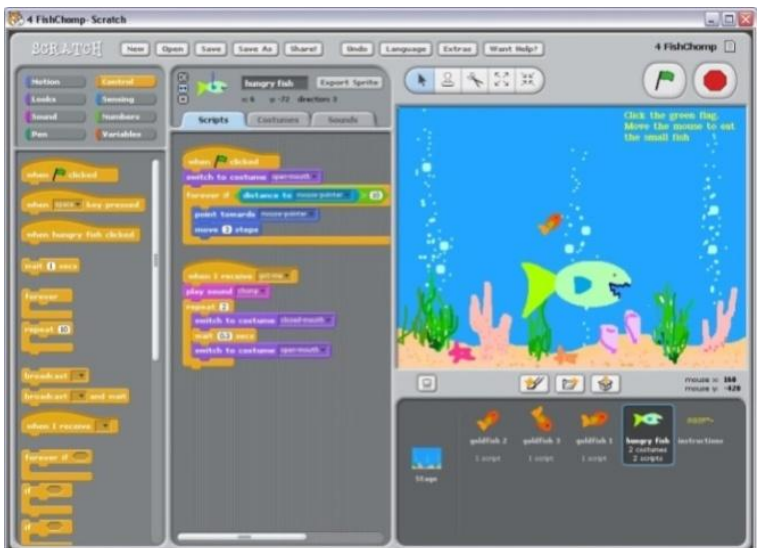

Figure 1. Scratch

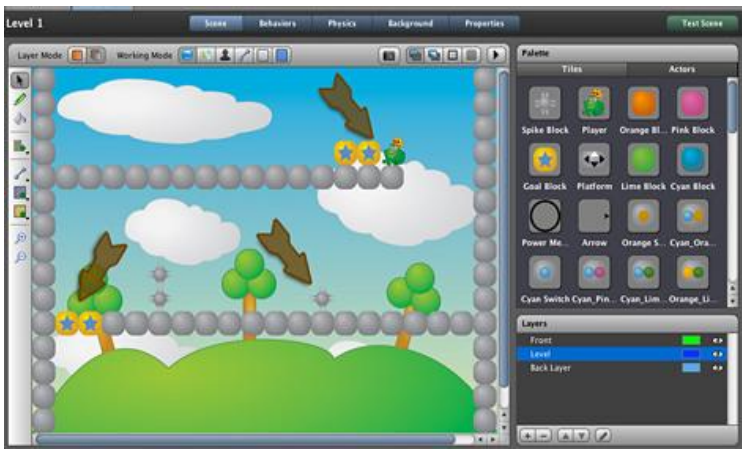

Figure 3. Stencylworks

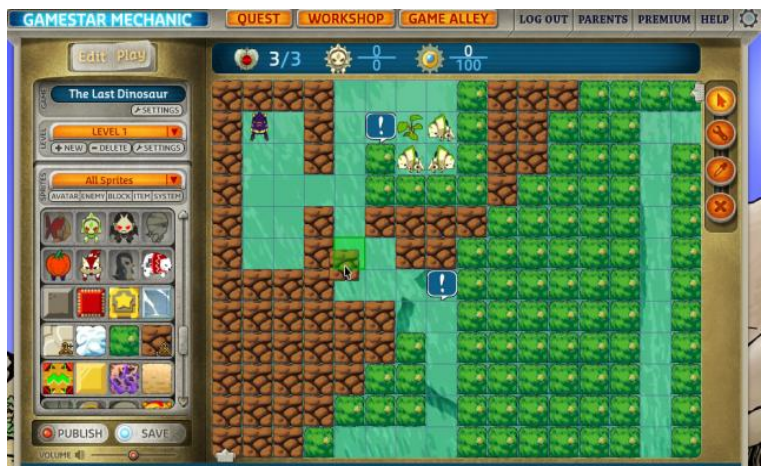

Figure 5. Gamestar Mechanic

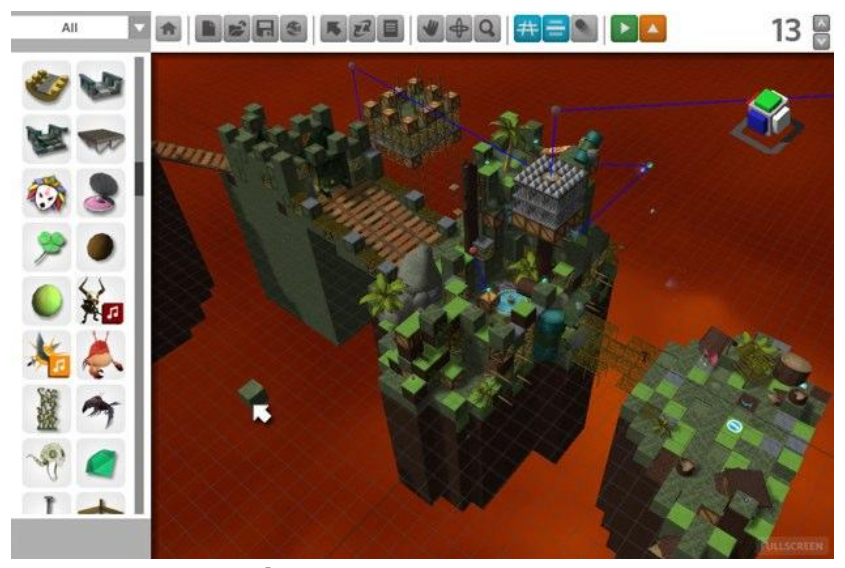

Figure 2. Atmosphir

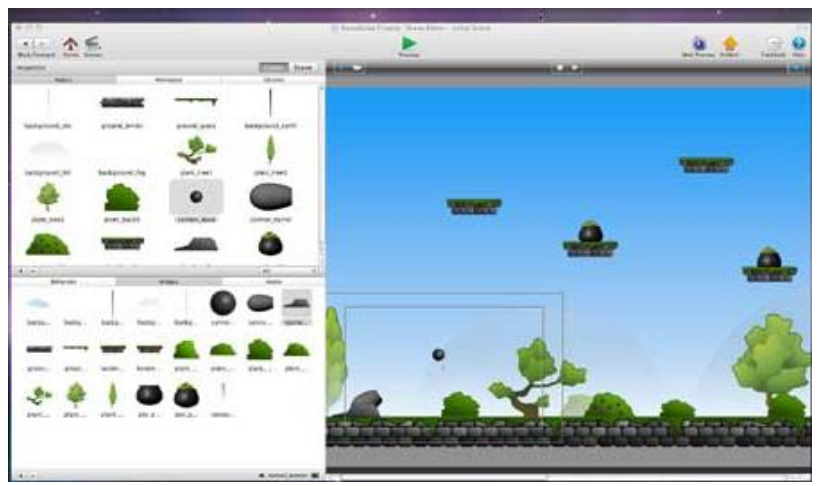

Figure 4. Game Salad

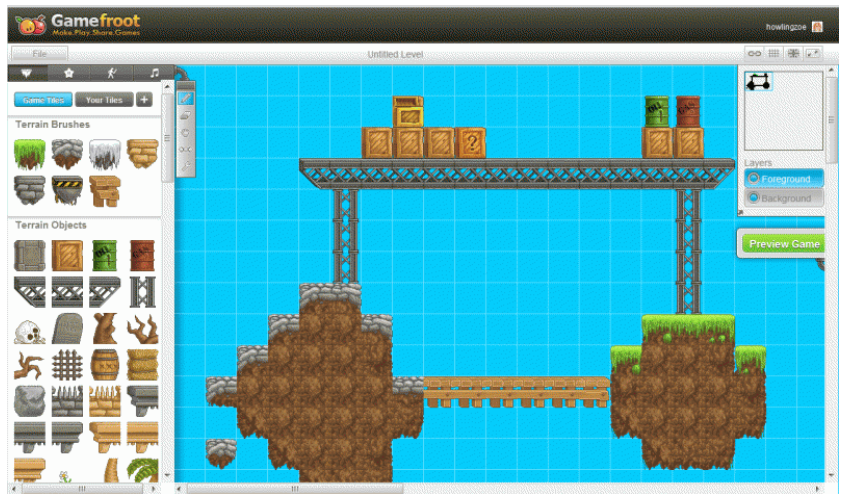

Figure 6. Gamefroot 